\title{
ADAR1p150 Forms a Complex with Dicer to Promote miRNA-222 Activity and Regulate PTEN Expression in CVB3-Induced Viral Myocarditis
}

\author{
Xincai Zhang ${ }^{1, \dagger}{ }^{\dagger}$ Xiangting Gao ${ }^{2, \dagger}{ }^{\text {, Jun Hu }} \mathrm{Hu}^{1}$, Yuxin Xie ${ }^{1}$, Yuanyi Zuo ${ }^{1}$, Hongfei $\mathrm{Xu}^{1, *}$ and \\ Shaohua Zhu ${ }^{1, *}$ \\ 1 Institute of Forensic Medicine, Soochow University, Suzhou 215021, China; xczhang1@stu.suda.edu.cn (X.Z.); \\ 11916@jsmc.edu.cn (J.H.); yxxie@stu.suda.edu.cn (Y.X.); snxie@stu.suda.edu.cn (Y.Z.) \\ 2 Department of Pathology, School of Medicine, Shihezi University, Shihezi 215021, China; \\ 20154221095@stu.suda.edu.cn \\ * Correspondence: xuhongfei@suda.edu.cn (H.X.); zhushaohua@suda.edu.cn (S.Z.); \\ Tel./Fax: +86-512-6512-5019 (H.X. \& S.Z.) \\ + These authors contributed equally to this work.
}

Received: 16 December 2018; Accepted: 4 January 2019; Published: 18 January 2019

\begin{abstract}
Adenosine deaminases acting on RNA (ADAR) are enzymes that regulate RNA metabolism through post-transcriptional mechanisms. ADAR1 is involved in a variety of pathological conditions including inflammation, cancer, and the host defense against viral infections. However, the role of ADAR1p150 in vascular disease remains unclear. In this study, we examined the expression of ADAR1p150 and its role in viral myocarditis (VMC) in a mouse model. VMC mouse cardiomyocytes showed significantly higher expression of ADAR1p150 compared to the control samples. Coimmunoprecipitation verified that ADAR1p150 forms a complex with Dicer in VMC. miRNA-222, which is involved in many cardiac diseases, is highly expressed in cardiomyocytes in VMC. In addition, the expression of miRNA-222 was promoted by ADAR1p150/Dicer. Among the target genes of miRNA-222, the expression of phosphatase-and-tensin (PTEN) protein was significantly reduced in VMC. By using a bioinformatics tool, we found a potential binding site of miRNA-222 on the PTEN gene's $3^{\prime}$-UTR, suggesting that miRNA-222 might play a regulatory role. In cultured cells, miR-222 suppressed PTEN expression. Our findings suggest that ADAR1p150 plays a key role in complexing with Dicer and promoting the expression of miRNA-222, the latter of which suppresses the expression of the target gene PTEN during VMC. Our work reveals a previously unknown role of ADAR1p150 in gene expression in VMC.
\end{abstract}

Keywords: ADAR1p150; viral myocarditis; miRNA-222; PTEN

\section{Introduction}

It has been well documented that viral myocarditis (VMC) is a primary cause of sudden death and heart failure in young adults [1-3]. Coxsackievirus B3 (CVB3), belonging to the Picornaviridae family of genus Enterovirus [4], is regarded as the most common infectious pathogen responsible for VMC and the subsequent pathogenesis of dilated cardiomyopathy (DCM) [5]. CVB3 induces VMC either through inflammatory mechanisms or through a direct cytopathic effect (CPE) [6-9]. The prevalence of acute myocarditis identified through routine necropsy is significantly higher than that through clinical diagnosis $[10,11]$, and the possible explanation for this discrepancy is that only a certain percentage of individuals with acute myocarditis develop easily observable clinical manifestations. Consistent with this, another study identified acute myocarditis as the cause of death at a rate of $\sim 1.5 \%$ in a total of 2560 autopsies but was suspected in only one of the cases in the clinic [12]. This indicates that 
$>97 \%$ of patients with lethal myocarditis do not have clinical presentations. Symptomless myocarditis may induce severe electrical dysfunction in the heart, and may even be life-threatening, particularly during exertion, which may explain the sudden death of young and vigorous individuals $[13,14]$. Therefore, CVB-induced VMC is not an unusual disease. Since it has a potentially lethal outcome, it is imperative to further understand the mechanisms underpinning its development so as to devise novel and effective therapeutics.

Adenosine deaminases acting on RNA (ADAR) are the enzymes that convert adenosine residues into inosine (A-to-I RNA editing) in double-stranded RNAs [15]. This generates changes in the structural and functional characteristics of both the RNA itself and the translated protein, causing significant functional consequences. The mammalian ADAR gene family contains three members: ADAR1, ADAR2, and ADAR3 [16,17]. ADAR1 and ADAR2 exhibit deaminase activity but ADAR3 does not seem to have an enzymatic function [15]. Thus far, ADAR1 has two known isoforms, a shorter and constitutively active ADAR1p110a, and a full-length interferon-inducible ADAR1p150. ADAR1p150 predominantly occupies the cytoplasm, while ADAR1p110 is restricted to the nucleus, suggesting that these two isoforms exhibit distinct functions [18].

In addition to the above-mentioned editing function, i.e., A-to-I sequence change, ADAR can also fulfill its duties via an editing-independent mechanism. ADAR2, either catalytically active or inactive, was shown to mediate mir-376a2 processing by interfering with the processing of Drosha, suggesting that ADAR exhibits two distinct functions: RNA editing and RNA binding [19]. In addition, a physical interaction between ADAR1 and Dicer, thus forming a functional complex, has also been reported [20]. In addition, in metastatic melanoma, ADAR1 was shown to mediate Dicer expression through let-7 [21], and in MKN-45 (a gastric cancer cell), ADAR1 promoted miRNA processing [22]. This ADAR1/Dicer heterodimer elevates the maximum pre-miRNA cleavage rate and accelerates the loading of miRNA onto the RISC complex, subsequently enhancing the silencing of the target gene.

The major known function of ADAR1 is to mediate the immune response of cells to viral infection. It can either promote or diminish viral replication in a virus-dependent manner [23], as evidenced by the findings that ADAR1 is increased in response to various stresses, and exhibits either pro-inflammatory or anti-inflammatory activity, depending on the specific type of insult [24-26]. However, little is known about the involvement of ADAR1 in the pathology of viral myocarditis and the subsequent inflammation. We hypothesized that ADAR1 might be critical in the VMC pathology. In this study, we assessed the expression of ADAR1 in a mouse VMC model and used neonatal rat cardiomyocytes (NRC) and $\mathrm{H} 9 \mathrm{c} 2$ cells as an in vitro model system to explore the implication of ADAR1 in the pathology of VMC.

\section{Results}

\subsection{Verification of the VMC Mouse Model}

BALB/c mice were injected with CVB3 or with MEM Eagle as a control. CVB3-infected mice developed symptoms such as irritability, infirmity, depression, and were less activity. On day 3 after infection, a few scattered small foci in the cardiac tissues of CVB3-treated mice were noted, indicating the presence of myocyte necrosis. On day 7 after infection, CVB3-infected mice exhibited extensive myocardial necrosis and inflammatory cell infiltration, including many lymphocytes and macrophages in and around the necrotic foci. In contrast, inflammatory cells and necrosis were barely seen in the cardiac tissues of control mice (Figure 1). 


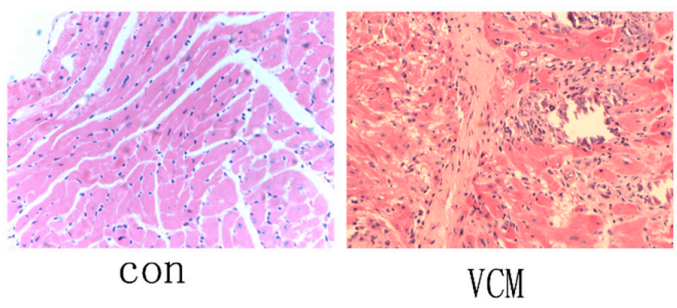

Figure 1. H\&E stain of the left ventricle of mice from the control and viral myocarditis (VMC) groups (original magnification 9100). Many macrophages and lymphocytes had infiltrated the myocardium on day 7 after infection.

\subsection{ADAR1 Expression in the Mouse Model of VMC and Cardiac Cell Lines Infected with CBV3}

We next assessed by immunohistochemistry and Western blot the expression levels of ADAR1 in the hearts from mice from the control and VMC groups. As shown in Figure 2A, VMC mouse hearts showed increased expression of ADAR1 compared with the control hearts, and the expression was localized in the cytoplasm.

A

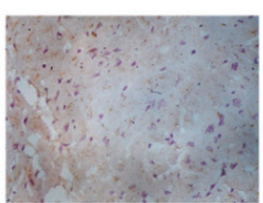

con

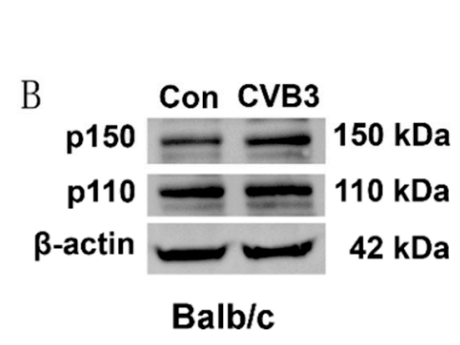

C

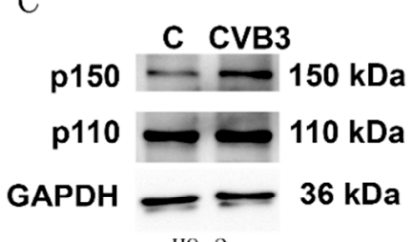

$\mathrm{H} 9 \mathrm{c} 2$
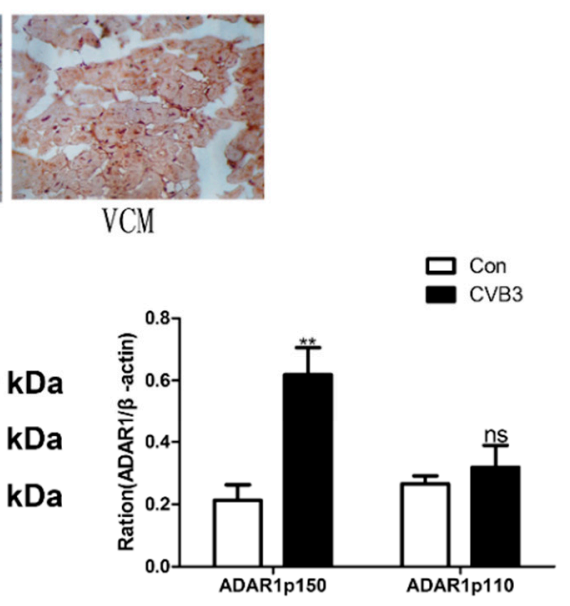

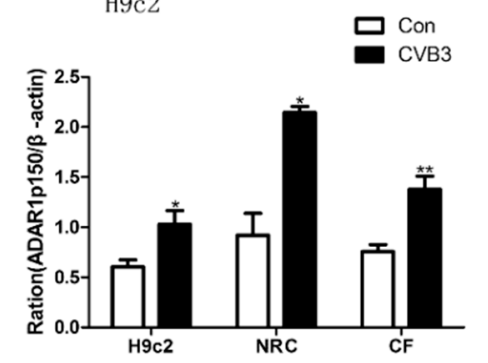

C CVB3
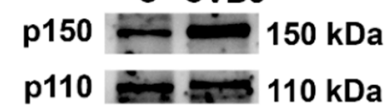

$\beta$-actin

NRC

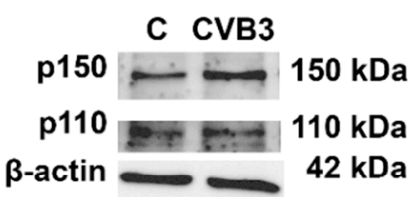

$\mathrm{CF}$

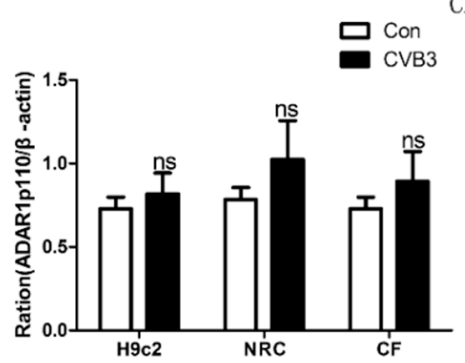

Figure 2. Adenosine deaminases acting on RNA 1 (ADAR1) expression in the hearts of VMC mice and CBV3-infected H9c2cells. (A) Immunohistochemical staining revealed that ADAR1 occupied the cytoplasm and its expression was increased in the cardiomyocytes from the VMC mice (original magnification $200 \times$ ). (B) The expression of ADAR1p150 was increased in VMC (BALB/c mice) on the seventh day after infection, while ADAR1p110 was not. (C) The same method was used to analyze changes inADAR1 in the H9c2 cell line, primary cardiac myocytes (NRCs), and cardiac fibroblasts (CFs), respectively, $48 \mathrm{~h}$ after CVB3 infection; the result is consistent with heart tissue. ${ }^{*} p<0.05,{ }^{* *} p<0.01$. 
We found that the expression of ADAR1p150 was elevated in cardiomyocytes from the VMC mice, while ADAR1p110 was not significantly changed (Figure 2B). Similar results were found in neonatal rat cardiomyocytes (NRC), H9c2 cells, and cardiac fibroblasts (CF) that had beeninfected with CBV3 for $48 \mathrm{~h}$ (Figure 2C).

\subsection{Interaction between ADAR1 and Dicer in the Hearts fromVMC Mice and in CBV3-Infected H9c2 Cells}

Coimmunoprecipitation between ADAR1 and Dicer was performed to determine whether ADAR1 protein contributes to the regulation of Dicer (Figure 3). Our data suggest that ADAR1 tightly bound to Dicer in the VMC mouse hearts and H9c2cells infected with CBV3, suggesting that the interaction was direct.

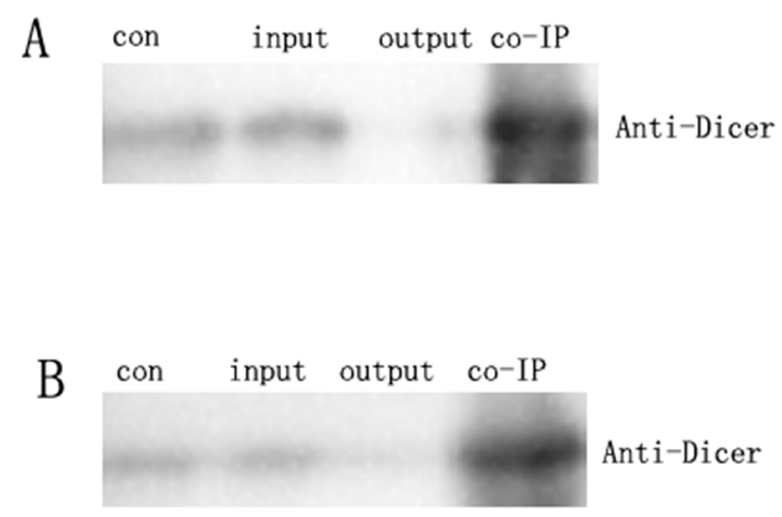

Figure 3. (A)ADAR1p150 promotes Dicer complex formation. ADAR1p150 interacts with Dicer in the VMC mouse model. (B) ADAR1p150 promotes Dicer complex formation. ADAR1p150 interacts with Dicer in the CBV3-infected H9c2 cells. Coimmunoprecipitation analysis was performed with the indicated antibodies. The experiment was conducted three times.

\subsection{Increased Level of miRNA-222 in the Hearts of VMC Mice and in CBV3-Infected H9c2 Cells}

To explore the relations between miRNAs and the interaction of ADAR1 with Dicer, we used RT-qPCR to detect changes in microRNA-221, $-222,-17,-151$, and -432 , which are related with the progress of virus infection and heart disease [27-29]. Compared with the control group, we found that the level of miRNA-222 was significantly higher; the others did not achieve statistical significance (Figure 4A). Based on changes in the miRNAs, we selected miRNA-222 and explored its role in NRC and CF. Interestingly, we found that miRNA-222 was also significantly elevated after infection with CVB3 compared with the control group (Figure 4B).

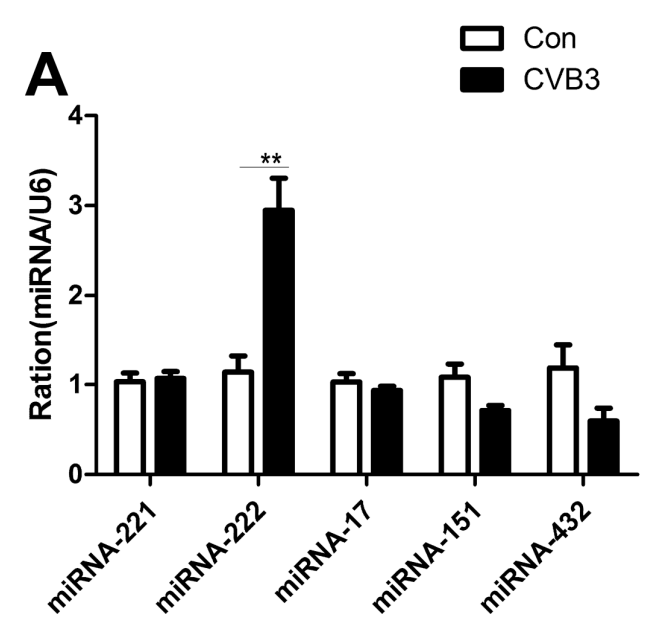

Figure 4. Cont. 

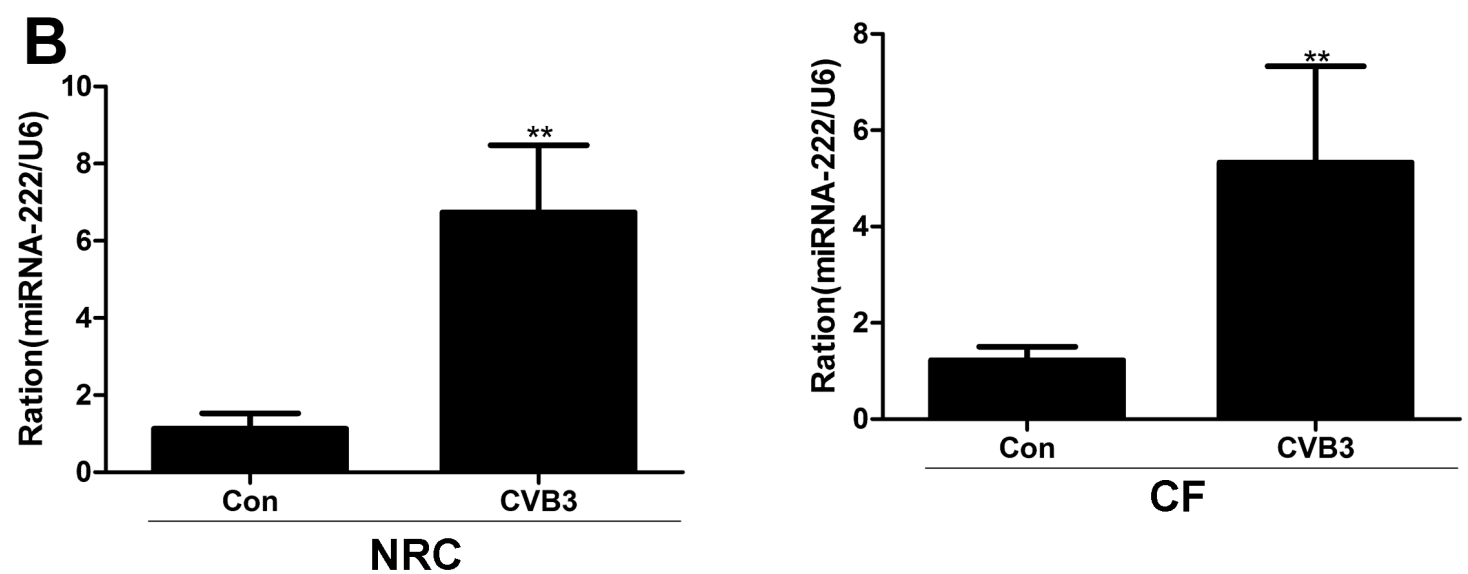

Figure 4. Increased level of miRNA-222 in VMC in the mouse model of VMC and cardiac cell lines infected with CBV3. (A) RT-qPCR was used to detect changes inmiRNA-221, -222, -17, -151, and -432, respectively, in myocardial tissue. (B) The miRNA-222 of relative quantification was further determined in primary cardiac myocytes and cardiac fibroblasts. Data represent the mean $\pm \mathrm{SEM}$ from the control (Con) and CVB3-infected groups, ${ }^{* *} p<0.01$.

\subsection{Effects of ADAR1p150 on miRNA-222 Synthesis in Cultured Cells}

The single most striking observation to emerge from the data comparison was that the levels of ADAR1p150 andmiR-222 were upregulated in VMC. Interestingly, the next question was whether the regulation of miRNA-222 was related to interactions between ADAR1p150and miR-222. To further demonstrate the effects of ADAR1p150on miR-222 synthesis in cultured cells, we knocked in the gene of ADAR1p150 in H9c2 cells and CFs as depicted in Figure 5A. The upregulation in the protein level of ADAR1p150 indicated the successful knock-in of the ADAR1p150 gene (Figure 5B). We observed that the miRNA-222 expression level was elevated by approximately $200 \%$ in $\mathrm{H} 9 \mathrm{c} 2$ cells and CFs (Figure 5B). However, when ADAR1p150 was knocked down, the results of miRNA-222 were reduced by $60-70 \%$ (Figure $5 \mathrm{C}$ ). The above results indicate that ADAR1p150 could promote the expression of miRNA-222. cell lines.

Together, these findings suggest that ADAR1p150 has an effect on miRNA-222 synthesis in cardiac

\section{6. miR-222 Downregulation ofPTEN Expression}

PTEN was shown as a miR-222 mediator in the regulation of cell survival, migration, proliferation, and apoptosis $[30,31]$. In the present study, we examined the expression level of PTEN protein, which gradually decreased in H9c2 cells and CFs when ADAR1p150 was upregulated (Figure 5B). When ADAR1p150 was knocked down, the expression level of PTEN protein was increased (Figure 5C).

To evaluate the ability of miR-222 to regulate the expression level of endogenous PTEN protein in cardiac myocytes, we used TargetScan to predict the putative targets [32]. The miR-222 putative binding sites were found in the 3'-UTR of PTEN at 1269-1275 bp (Figure 6A). Then, we assessed the impact of miR-222 on PTEN expression in H9c2 cells. RT-qPCR and Western blot analysis demonstrated that miR-222 suppressed the protein levels of PTEN by approximately $40 \%$ in H9c2 cells compared to the control (Figure 6B,C). Correspondingly, mis-RNA-222 (a negative control) did not influence PTEN expression, but miR-222 inhibitor increased the PTEN level (Figure 6B,C). Taken together, miR-222 probably regulates cardiomyocyte apoptosis by suppressing PTEN expression, confirming the previous reports. 

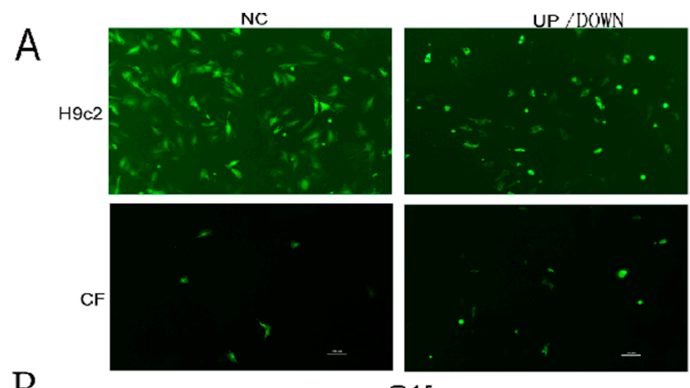

B

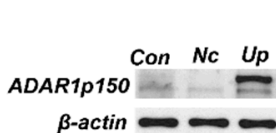

$\beta$-actin $-\infty$

$\mathrm{H} 9 \mathrm{c} 2$
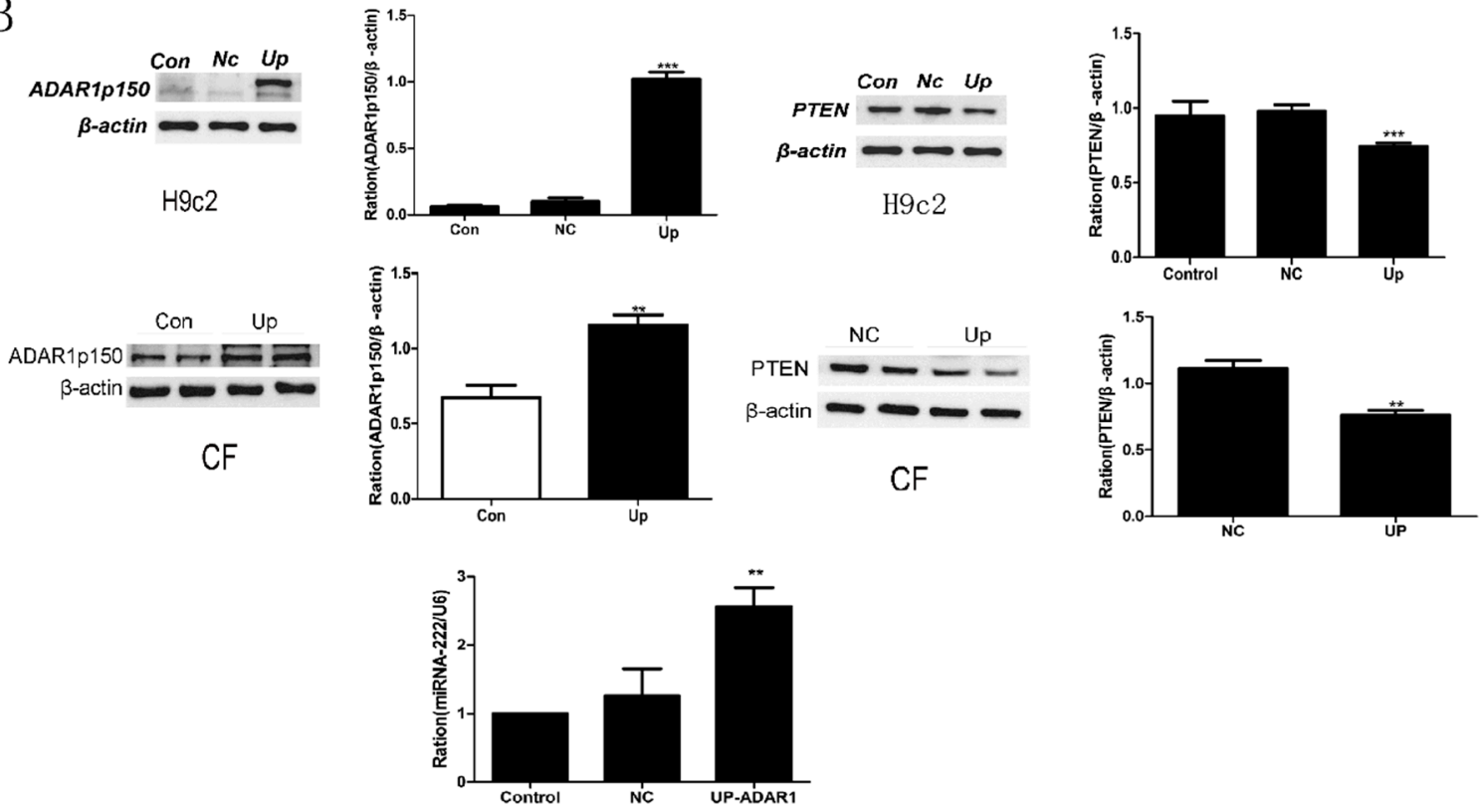

$\mathrm{H} 9 \mathrm{c} 2$

C
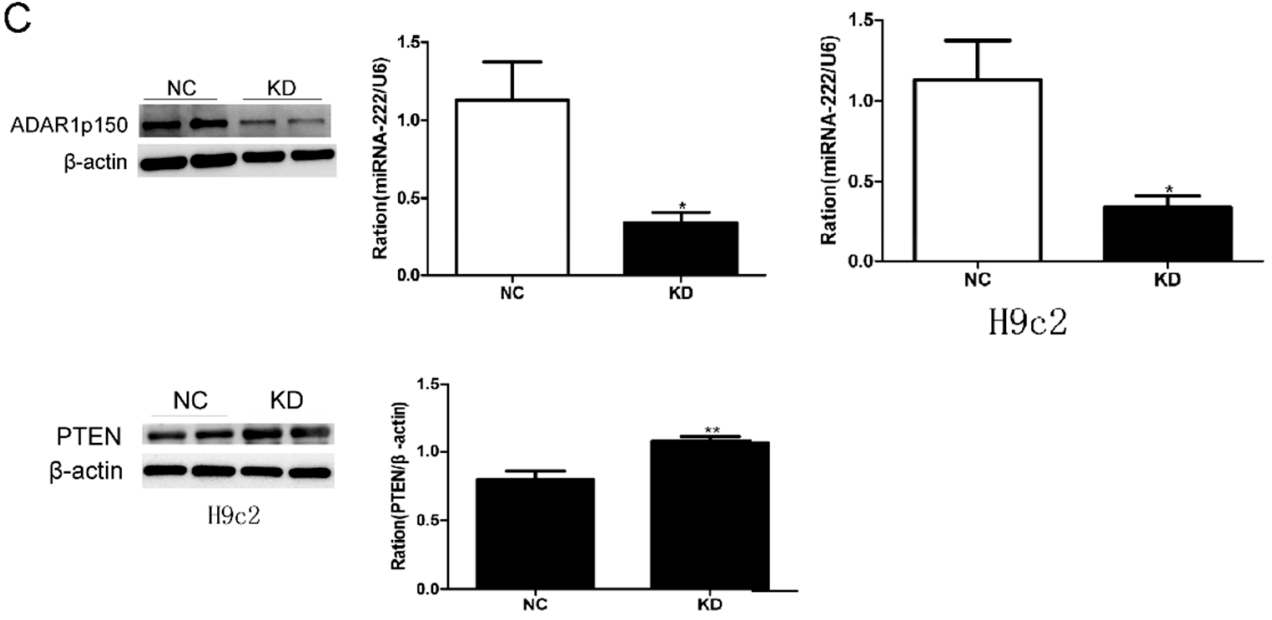

Figure 5. Effects of ADAR1p150 on miRNA-222 synthesis in cultured cells and regulation of phosphatase-and-tensin (PTEN) expression by miRNA-222. (A) GFP as a marker protein was detected by immunofluorescence after $48 \mathrm{~h}$ transfection in the H9c2 cell line and CFs (cardiac fibroblasts). As shown in the picture, the transduction efficiency was always over $80 \%$. (B) After confirming that ADAR1p150 high expression transfection was successful, miRNA-222 and PTEN were quantitatively or relatively quantified. (C) After inhibiting the expression of ADAR1P150, miRNA-222 and PTEN were quantitatively or relatively quantified. Data represent the mean \pm SEM from the control (Con)and infected groups, negative control (NC)knocked down (KD), ${ }^{*} p<0.05,{ }^{* *} p<0.01,{ }^{* * *} p<0.001$. 


\section{A Position 5104-5110 of PTEN 3' UTR 5' ... UACAAGCAGGAACUACUACUGAU... \\ miRNA-222 3' UCCUAGAUGUGACCGAUGACU}

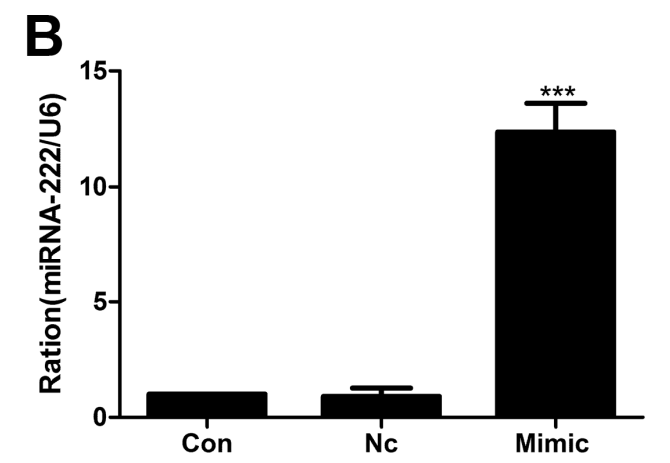

C
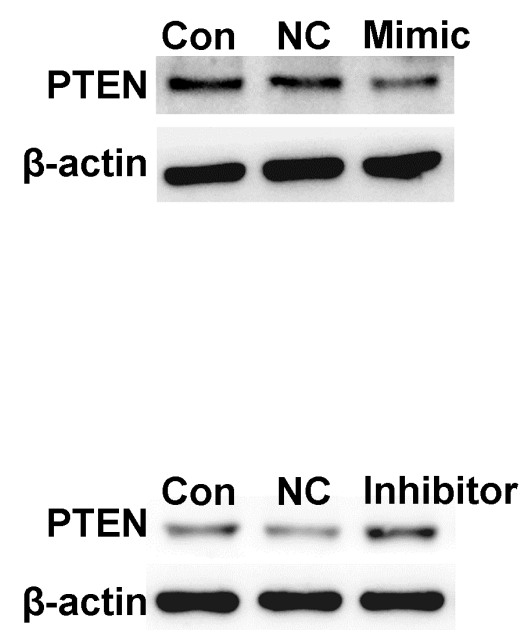
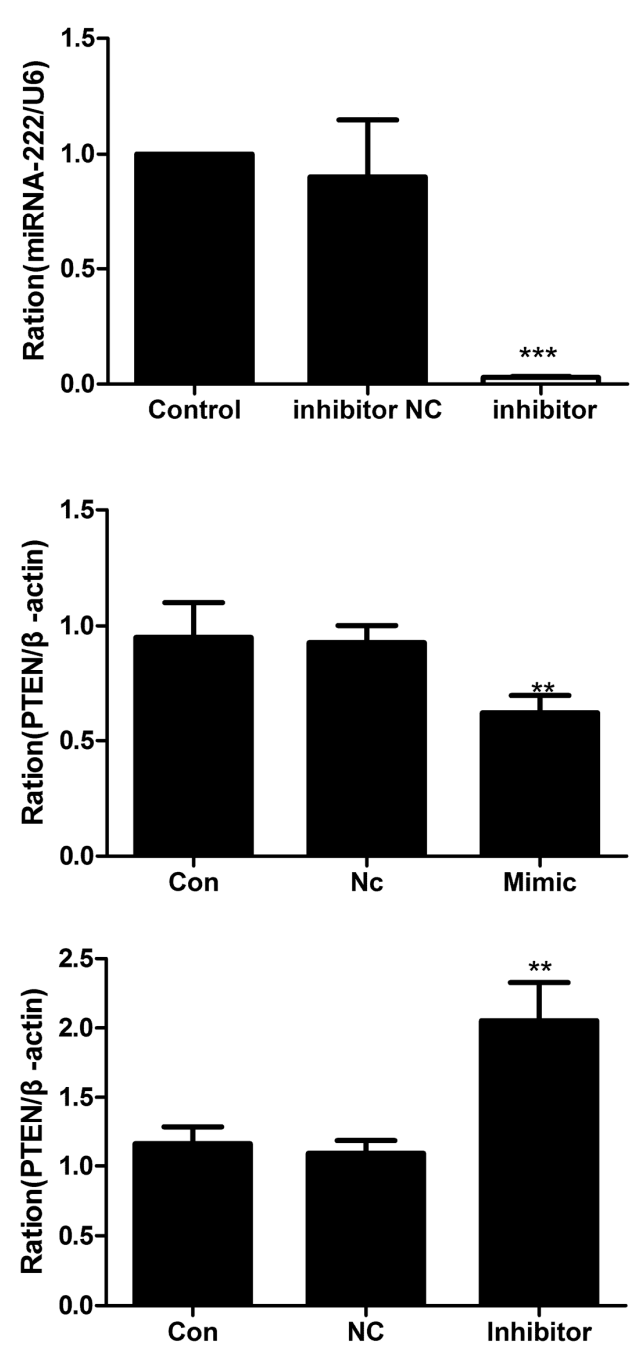

Figure 6. PTEN is a target protein of miRNA-222. (A) According to the principle of base pairing to deduce the binding of miR-222 to the predicted sequence in the $3^{\prime}$-UTR of mouse PTEN mRNAs, seven complementary sites were demonstrated. (B) We successfully transferred the mimic and inhibition of miRNA-222 into H9c2 cells, as determined by quantitative-PCR. (C) The change in PTEN protein in $\mathrm{H} 9 \mathrm{c} 2$ cells when miRNA-222 was upregulated and downregulated, respectively. NC = negative control. Data represent the mean \pm SEM from the Con and infected groups, ${ }^{* *} p<0.01,{ }^{* * *} p<0.001$.

\subsection{Regulation of PTEN by miRNA-222 Triggered by ADAR1p150 in CVB3-Induced Myocarditis}

Next, we want to discuss whether the regulation process of ADAR1p150 to PTEN is dependent on miRNA-222. When the H9c2 cell line was infected with CVB3 (the ADAR1p150 was upregulated), PTEN expression was downregulated (Figure 7). Moreover, co-transfection of the miRNA-222 inhibitor almost eliminated the effect of ADAR1p150 (Figure 7). This demonstrates that ADAR1p150 specifically regulates the interaction between miRNA-222 and Dicer, and changes the expression of the PTEN protein in VMC. 

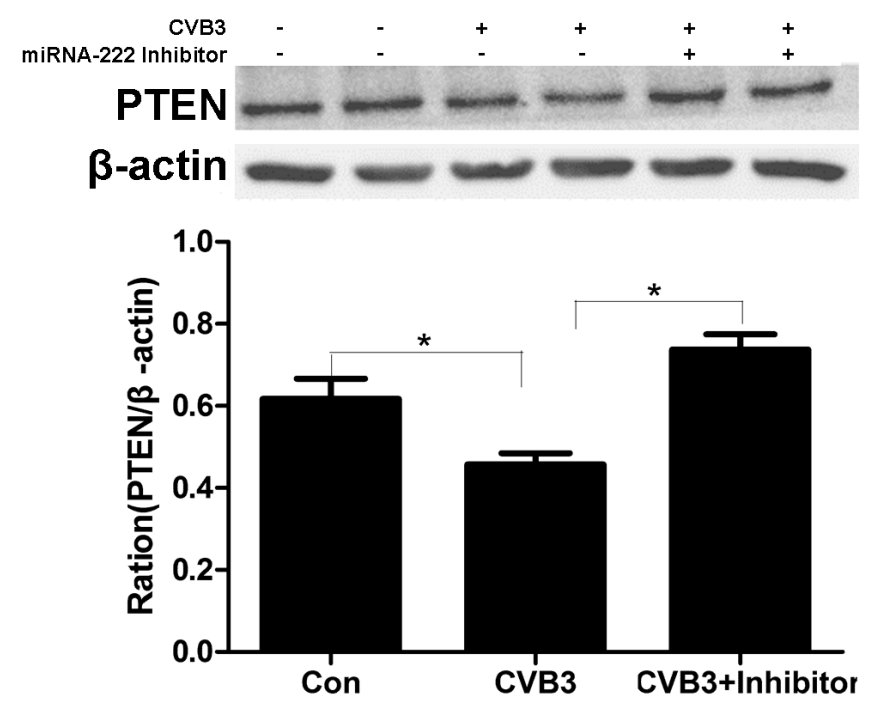

Figure 7. PTEN regulation by miRNA-222 in hearts of VMC mice. The PTEN expression was downregulated when $\mathrm{H} 9 \mathrm{c} 2$ cells were infected with $\mathrm{CVB} 3\left({ }^{*} p<0.05\right)$. When we co-transfected the miRNA-222 inhibitor, the effect of ADAR1p150 almost disappeared.

\subsection{ADAR1p150 Plays an Important Role in Maintaining Cell Viability by Regulating PTEN Expression}

PTEN has been shown to be an apoptosis-associated protein [33]. Given the strong correlation of ADAR1p150 with PTEN through regulating miR-222 in VMC, we investigatedADAR1p150 in cell viability of NRC infected with CVB3. We knocked down ADAR1p150 in NRC infected with CVB3. We performed CCK-8 to check the effect of ADAR1p150 on the cell viability. Compared with the control group, the value of CCK-8 was reduced significantly after 24 and $48 \mathrm{~h}(p<0.05$, Figure $8 \mathrm{~A})$. The expression of PTEN was evaluated $(p<0.05$, Figure 8 B). In addition, we found that the expression of the pro-apoptotic protein BAX was increased and the expression of the anti-apoptotic protein Bcl-2 was reduced compared with the control group (Figure $8 \mathrm{~B}, p<0.05$ ). Our data indicate that ADAR1p150 may play a crucial role in anti-apoptosis in the pathogenesis of viral myocarditis.
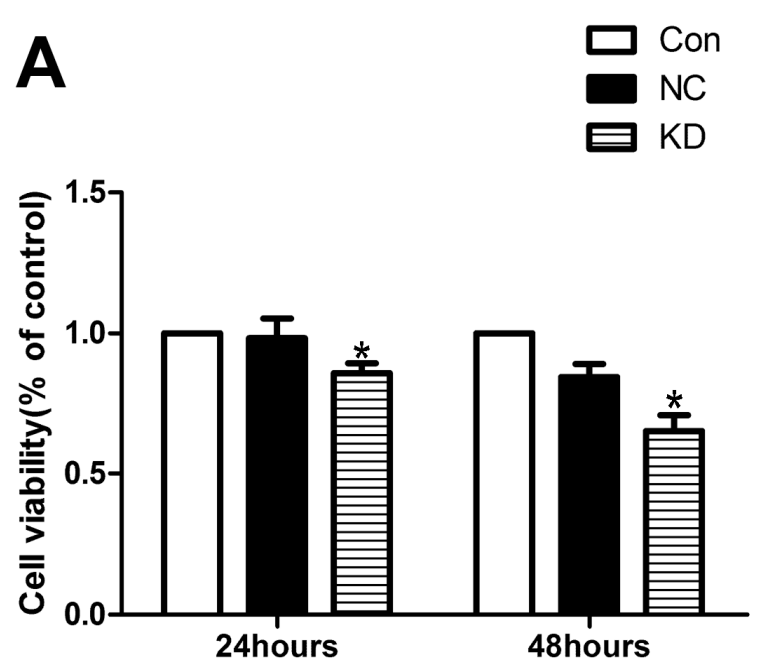

Figure 8. Cont. 
B

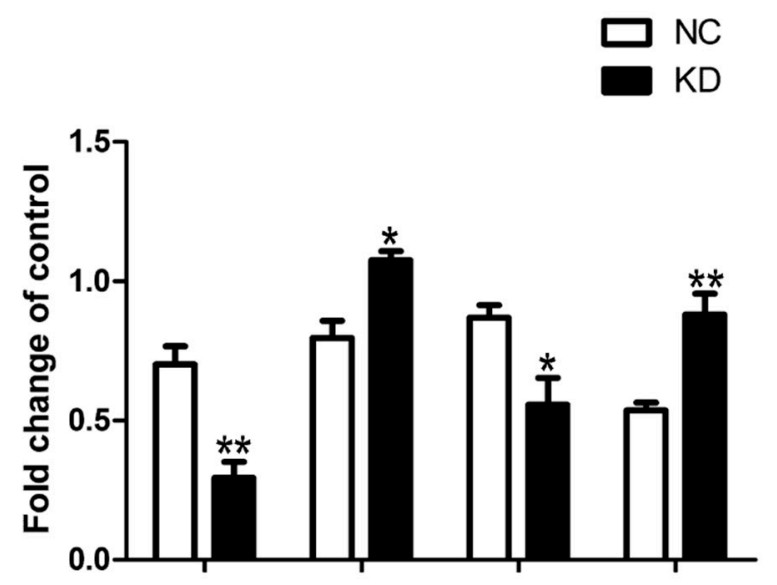

Figure 8. The effect of ADAR1p150 on cell viability in NRC infected with CVB3. (A) The value of CCK-8was significantly reduced after we knocked down ADAR1p150 in the NRC infected with CVB3 at 24 and $48 \mathrm{~h}\left({ }^{*} p<0.05\right)$. (B) The expression of PTEN and BAX were evaluated $\left({ }^{*} p<0.05,{ }^{* *} p<0.01\right)$ and Bcl-2 was reduced compared with the control group $\left({ }^{*} p<0.05\right)$.

\section{Discussion}

VMC is a primary cause of cardiomyopathy in young adults and is linked to arrhythmia, heart failure, and even sudden death [34]. Several supportive treatments, including anti-virus, anti-oxidation therapies, and immune suppression, have been used to reverse or even block the hyperactive myocardial inflammation caused by viral infection; however, in the clinic, these approaches have not been efficient enough to improve patient survival [34-36]. Hence, VMC remains challenging with regard to the efficacy of treatments, and further elucidation of the fundamental mechanisms leading to VMC is essential [37-39].

MicroRNAs (miRNAs) mediate a diversity of cellular activities through the repression of target gene expression. Drosha and Dicer are integral parts of the miRNA functional machinery [40]. Drosha, forming a complex with DGCR8 (a dsRNA-binding protein) in the nucleus, cleaves primary transcripts of miRNAs (pri-miRNAs) to generate pre-miRNAs. Pre-miRNAs are then exported into the cytoplasm and cleaved by Dicer, thereby generating mature 21-24nt mature miRNAs [40]. Many studies have revealed a crucial role of miRNAs in the pathogenesis of VMC [41,42]. ADAR1 is involved in a variety of pathological conditions including inflammation [43,44], host defense against viral infections [45], and cancer $[20,46,47]$. Recent studies suggest that ADAR1 possesses two capabilities, one as an RNA editing enzyme, which involves A-to-I RNA editing that regulates RNA metabolism [20,48-52], and the other as an RNAi machinery component by complexing with Dicer [20].

The results of our study showed that ADAR1p150 expression in VMC was elevated, and the major part of immunostaining was localized in the cytoplasm. Similar results were found in cardiac cell lines infected with CVB3. Dicer, an endoribonuclease of the RNase III family, regulates the maturation of most miRNAs and, thus, has a significant role in numerous biological events. The evidence that ADAR/Dicer promotes miRNA processing was revealed. In our study, the elevated expression of ADAR1p150 waspredominantly localized in the cytoplasm of cardiac myocytes, the same location as Dicer, which produces mature miRNAs. Hence, we considered it reasonable to test the hypothesis that the elevated expression of ADAR1p150 has an effect on Dicer protein in the pathology of this disease. Coimmunoprecipitation between ADAR1 and Dicer was performedto determine whether ADAR1 protein contributes to the regulation of Dicer. Our data suggest that ADAR1 bound tightly to Dicer in the mouse VMC model and H9c2cells infected with CBV3, suggesting that the interaction is direct. These results verified our hypothesis.

miR-222 is involved in inflammation, apoptosis and necrosis, fibrosis, hypertrophy, and cardiac remodeling [27]. For example, knockdown of miRNA-222 suppressed neointimal lesion formation and proliferation of vascular smooth muscle cell (VSMC) after carotid angioplasty [53]. In this 
study, miRNA-222 was highly expressed in cardiomyocytes of VMC mouse hearts and cardiac cell lines infected with CVB3. To verify whether the highly expressed miRNA-222 was related to ADAR1p150, we knocked down the gene of ADAR1p150 in cardiac myocytes and found miRNA-222 changed correspondingly. These data indicate that ADAR1p150 mediates miRNA-222 synthesis in the pathogenesis of VMC.

We next investigated the effect of miRNA-222 on VMC. We first identified a potential binding site for mouse miR-222 and PTEN through TargetScan. PTEN is a multifunctional tumor suppressor whose major function is mediated via its lipid phosphatase activity [54-56]. PTEN acts as a mediator of several cellular events including apoptosis, cell survival, proliferation, and migration [57-59]. Recently, PTEN has been shown to mediate the function of cardiovascular and pulmonary systems $[60,61]$. For instance, PTEN regulates pulmonary SMC proliferation and survival, as well as cardiomyocyte hypertrophy [60,61]. Gong et al. [62] verified that the 3'-UTR of the PTEN gene contains the sequence of nucleotides complementary to the $5^{\prime}$ end of miRNA-222, and its activity was mediated by miRNA-222 through a reporter assay. In the present study, we used a bioinformatics tool and identified a binding site of miRNA-222 in the mouse PTEN 3'-UTR. We further demonstrated that miR-222 suppressed the expression of PTEN in cardiomyocytes. Taken together, we argue that the elevated miRNA-222 levels observed in the hearts of VMC mice are likely to contribute to the VMC pathogenesis.

In cardiac myocytes, the pro-apoptotic effect of PTEN has been proven [63]. We found the expression level of PTEN protein gradually decreased when ADAR1p150 was upregulated in cardiac myocytes. In contrast, when ADAR1p150 was knocked down, the expression level of PTEN protein was increased. The PTEN expression was downregulated when H9c2 cells were infected with CVB3 and when we co-transfected the miRNA-222 inhibitor, the effect of ADAR1p150 almost disappeared. To validate the role of PTEN in the anti-apoptotic function of ADAR1p150, we knocked down ADAR1p150 in the NRC infected with CVB3.The value of CCK-8 was reduced in the group in which ADAR1p150 was reduced significantly in the presence of CVB3 at 24 and $48 \mathrm{~h}$ after transfection. The protein level of PTEN was evaluated, and BAX and Bcl-2 changed correspondingly. These findings support the notion that PTEN plays essential roles in cell survival, proliferation, and apoptosis. These observations are also in line with a recent finding that ADAR may change the miRNA's function via an editing-independent mechanism.

\section{Materials and methods}

\subsection{Animals}

All animal experiments were performed in compliance with the Guide for the Care and Use of Medical Laboratory Animals (Ministry of Health, China, 1998), and approved by the Institutional Animal Care and Use Committee at Soochow University (ECSU-201800094; 10 November 2017).

\subsection{VMC Mouse Model}

CVB3 viral stock was obtained as detailed previously [64]. A total of $30 \mathrm{BALB} / \mathrm{c}$ mice (male, 4-6 weeks old, 16-20 g) were intraperitoneally (i.p.) injected with $5 \times 10^{4}$ plaque-forming units (PFU) of purified CVB3 as described previously [65]. Ten mice were i.p. injected with MEM Eagle as the control. Seven days post infection/injection, mice were sacrificed by pentobarbital injection ( $40 \mathrm{mg} / \mathrm{kg}$, i.p.) and the hearts were excised for biochemical and histological experiments. Heart tissue that contained the left and right ventricles were fixed in $4 \%$ paraformaldehyde $(\mathrm{pH} 7.2)$ and paraffin-embedded for histological analysis. The remaining cardiac tissues were snap-frozen in liquid nitrogen for subsequent studies.

\subsection{Histology and Immunohistochemistry}

Murine tissue was stained as described elsewhere [66]. Tissue sections were prepared at 4- $\mu \mathrm{m}$ thickness. Immunohistochemical staining for ADAR1 (Santa Cruz Biotechnology, Dallas, TX, USA) 
was performed as previously described [66]. All slides were counterstained with hematoxylin. Slides were viewed with a Zeiss Axioskop 40 microscope (Carl Zeiss, Jena, Germany).

\subsection{Culture of Cardiomyocytes and Fibroblasts}

Cardiomyocytes were prepared through trypsin digestion from neonatal mice within $72 \mathrm{~h}$ of birth, as previously detailed [67]. Cardiac fibroblasts and cardiomyocytes were separated through pre-plating. Cardiomyocytes isolated by this method were cultured in collagen-pre-coated culture wells, and 95\% exhibited typical cardiomyocyte structure. Isolated cardiac fibroblasts were cultured in DMDM supplemented with 10\% FBS.

\subsection{H9c2 Cell Culture}

H9c2 cells, a cardiac cell line (CRL146, ATCC), were grown at a density of approximately $10^{5}$ cells $/ \mathrm{cm}^{2}$ and cultured as monolayers in DMEM supplemented with $10 \%$ FBS, nonessential amino acids (1\%), streptomycin $(100 \mu \mathrm{g} / \mathrm{mL})$ and penicillin (100 IU), and glutamine $(2 \mathrm{mM})$, in a $37{ }^{\circ} \mathrm{C}$ incubator with $5 \% \mathrm{CO}_{2}$ and water vapor. The medium was replenished every 2 days.

\subsection{Western Blots}

Cardiac tissues and transfected cells were homogenized in RIPA buffer (Heart, Beijing, China). BCA Protein Assay Kit was used to determine the protein concentrations. Then, $50 \mu \mathrm{g}$ of total protein per sample was subjected to $12 \%$ sodium dodecyl sulfate-polyacrylamide gel electrophoresis (SDS-PAGE), followed by transfer to a PVDF membrane (BioRad, Hercules, CA, USA). The membrane was then incubated with the primary antibody of interest, washed with PBS-T, and incubated with an appropriate secondary antibody. Protein bands were quantified with ImageQuant software. The $\beta$-actin level was used as an internal control. The following primary antibodies were used: ADAR1 (Santa Cruz Biotechnology, Dallas, TX, USA), Dicer (Biorbyt, Cambridge, UK), PTEN (Abcam, Cambridge, UK), BAX (Cell Signaling Technology, Danvers, MA, USA); Bcl-2 (Bioworld, Nanjing, China); $\beta$-actin (Cmctag, Shanghai, China); GAPDH (Cmctag, Shanghai, China). Three independent experiments were performed for each sample.

\subsection{Coimmunoprecipitation (Co-IP)}

Whole cell lysates were prepared in the lysis buffer $(10 \mathrm{mM}$ Tris- $\mathrm{HCl}$, pH7.5, $150 \mathrm{mM} \mathrm{NaCl}$, $1 \%$ Triton X-100, $25 \mu \mathrm{g} / \mathrm{mL}$ leupeptin, and $25 \mu \mathrm{g} / \mathrm{mL}$ aprotinin). Briefly, cells were lysed on ice for $20 \mathrm{~min}$ and centrifugated at $13,000 \times \mathrm{g}$ for $20 \mathrm{~min}$, followed by supernatant collection. The anti-ADAR1 antibody or anti-Dicer antibody was used to bind to the desired protein complex. Immunocomplex or MAG-Fc was precipitated with protein A-conjugated beads (Amersham Pharmacia Biotech, Little Chalfont, UK). The precipitates were subjected to Western blot analysis.

\subsection{Upregulation and Knockdownof ADAR1p150 Protein}

ADAR1p150 knockdown and up-expression vectors, as well as a negative control (NC), were purchased from GeneChem (Shanghai, China). The plasmid was delivered into the cells by the lipid carrier lip3000 (Thermo Fisher Scientific, Waltham, MA, USA). The small interfering RNA sequence for ADAR1p150 was 5'-AGGGACATGGGCTATGGGAAT-3'. Transfection results were confirmed by Western blot analyses after $48 \mathrm{~h}$.

\section{9. miRNA Synthesis and miRNA Inhibitor}

Murine miR-222 and its mutated RNA oligos were synthesized by RiboBio (Guangzhou, China). The sequences of miR-222 mimic and inhibitor were as follows $\left(5^{\prime}-3^{\prime}\right)$ : miR-222 mimic, AGCUACAUCUGGCUACUGGGU; miR-222 inhibitor, the sequence of the negative control (NC) is 
confidential. We transfected the cells by using lipo3000 (Thermo Fisher Scientific, Waltham, MA USA) for $48 \mathrm{~h}$.

\subsection{Transfection of miRNAs}

miRNA mimic, miRNA inhibitor, or siRNAs (Ribobio, Guangzhou, China) were transfected into cells seeded in 6-well dishes using lipo3000 (Thermo Fisher Scientific). After overnight (12 h) culture, cells were placed in fresh culture medium for an additional 6 or $24 \mathrm{~h}$ culture.

\subsection{RNA Purification andReverse Transcription Polymerase Chain Reaction (RT-PCR)}

Trizol was used to purify total RNA from heart tissue and cardiac cells according to the protocol provided by the manufacturer. After denaturing RNA at $95^{\circ} \mathrm{C}$ for $5 \mathrm{~min}$, RT-PCR was performed in a total volume of $20 \mu \mathrm{L}$ with the following protocol: $70^{\circ} \mathrm{C}$ for $5 \mathrm{~min}, 37^{\circ} \mathrm{C}$ for $5 \mathrm{~min}, 42^{\circ} \mathrm{C}$ for $60 \mathrm{~min}$, and $70{ }^{\circ} \mathrm{C}$ for $10 \mathrm{~min}$. After RT-PCR, 40 cycles of the PCR protocol $\left(95^{\circ} \mathrm{C}(10 \mathrm{~s})\right.$ and $\left.60{ }^{\circ} \mathrm{C}(40 \mathrm{~s})\right)$ wasfollowed in an ABI StepOne Plus Sequence Detection System (Applied Biosystems, Waltham, MA, USA). GAPDH or U6 was used as an internal control.

\subsection{Analysis of Cardiomyocyte Viability}

The cell counting kit-8 (CCK-8; Dojindo, Shanghai, China) was performed to measure the viability of cardiomyocytes. Briefly, equal amounts of cells were cultured in FBS (5\%)-L-DMEM in 96-wellplates for $24 \mathrm{~h}$ and then treated with CVB3 for 24 or $48 \mathrm{~h}$ after ADAR1p150 was knocked down. According to the supplier's instructions, $10 \mu \mathrm{L} /$ well of CCK-8 was added to each well for a further $3 \mathrm{~h}$ incubation at $37^{\circ} \mathrm{C}$. The ELx808 Absorbance Microplate Reader with an optical density (OD) at $450 \mathrm{~nm}$ was used to calculate cell viability.

\subsection{Statistical Analysis}

All data are presented as the mean \pm standard error of the mean (SEM). The two-tailed independent Student's $t$-test and ANOVA were used for the statistical analysis. $p<0.05$ was considered statistically significant. All statistical analyses were performed using SPSS, version 12.0 (SPSS Inc., Chicago, IL, USA).

\section{Conclusions}

In summary, we have demonstrated that ADAR1p150 promotes miRNA-222 through the formation of a complex with Dicer and, subsequently, that miRNA-222 regulates the expression of PTEN in VMC. ADAR1p150 plays an important role in maintaining cell viability. Our results provide novel insight into the mechanisms of viral myocarditis and point out that ADAR1 plays a key role in cardiac myocytes. By understanding the molecular basis underlying ADAR1p150 function, novel information might be offered. Such informationmay promote new therapeutics for VMC in the future. However, more research will be needed to understand how the editing-dependent and -independent mechanisms cooperate to alter the expression level and function of specific miRNAs and their target genes.

Author Contributions: Conceptualization: H.X., S.Z.; Methodology: X.Z.; Validation: X.G.; Formal analysis: J.H.; Investigation: X.Z., X.G., and J.H.; Resources: Y.Z.; Data curation: X.Z.; Writing \pm original draft: Y.X.; Writing \pm review \& editing: H.X.; Supervision: X.G.; Visualization: X.Z.; Project administration: H.X.; Funding acquisition: H.X., S.Z.

Funding: The study was supported by the National Nature Science Foundation of China (No. 81571848), the Science Foundation of Suzhou, China (No. sys2018056), and a project funded by the Priority Academic Program Development of Jiangsu Higher Education Institutions.

Conflicts of Interest: The authors declare no conflicts of interest. 


\section{References}

1. Cooper, L.T. Myocarditis. N. Engl. J. Med. 2009, 360, 1526-1538. [CrossRef] [PubMed]

2. Pankuweit, S.; Klingel, K. Viral myocarditis: From experimental models to molecular diagnosis in patients. Heart Fail. Rev. 2013, 18, 683-702. [CrossRef] [PubMed]

3. Sagar, S.; Liu, P.P.; Cooper, L.T. Myocarditis. Lancet Lond. Engl. 2012, 379, 738-747. [CrossRef]

4. Esfandiarei, M.; McManus, B.M. Molecular biology and pathogenesis of viral myocarditis. Annu. Rev. Pathol. 2008, 3, 127-155. [CrossRef] [PubMed]

5. Tam, P.E. Coxsackievirus myocarditis: Interplay between virus and host in the pathogenesis of heart disease. Viral Immunol. 2006, 19, 133-146. [CrossRef] [PubMed]

6. Van Linthout, S.; Savvatis, K.; Miteva, K.; Peng, J.; Ringe, J.; Warstat, K.; Schmidt-Lucke, C.; Sittinger, M.; Schultheiss, H.P.; Tschope, C. Mesenchymal stem cells improve murine acute coxsackievirus B3-induced myocarditis. Eur. Heart J. 2011, 32, 2168-2178. [CrossRef]

7. Chow, L.H.; Beisel, K.W.; McManus, B.M. Enteroviral infection of mice with severe combined immunodeficiency. Evidence for direct viral pathogenesis of myocardial injury. Lab. Investig. 1992, 66, $24-31$.

8. Yuan, J.P.; Zhao, W.; Wang, H.T.; Wu, K.Y.; Li, T.; Guo, X.K.; Tong, S.Q. Coxsackievirus B3-induced apoptosis and caspase-3. Cell Res. 2003, 13, 203-209. [CrossRef] [PubMed]

9. Mason, J.W.; O'Connell, J.B.; Herskowitz, A.; Rose, N.R.; McManus, B.M.; Billingham, M.E.; Moon, T.E. A clinical trial of immunosuppressive therapy for myocarditis. The Myocarditis Treatment Trial Investigators. N. Engl. J. Med. 1995, 333, 269-275. [CrossRef]

10. Wakafuji, S.; Okada, R. Twenty year autopsy statistics of myocarditis incidence in Japan. Jpn. Circ. J. 1986, 50, 1288-1293. [CrossRef]

11. Gravanis, M.B.; Sternby, N.H. Incidence of myocarditis. A 10-year autopsy study from Malmo, Sweden. Arch. Pathol. Lab. Med. 1991, 115, 390-392. [PubMed]

12. Carniel, E.; Sinagra, G.; Bussani, R.; Di Lenarda, A.; Pinamonti, B.; Lardieri, G.; Silvestri, F. Fatal myocarditis: Morphologic and clinical features. Ital. Heart J. 2004, 5, 702-706. [PubMed]

13. Ward, C. Severe arrhythmias in coxsackievirus B3 myopericarditis. Arch. Dis. Child. 1978, 53, $174-176$. [CrossRef] [PubMed]

14. Bendig, J.W.A.; O’Brien, P.S.; Muir, P.; Porter, H.J.; Caul, E.O. Enterovirus sequences resembling coxsackievirus A2 detected in stool and spleen from a girl with fatal myocarditis. J. Med. Virol. 2001, 64, 482-486. [CrossRef] [PubMed]

15. Keegan, L.P.; Leroy, A.; Sproul, D.; O'Connell, M.A. Adenosine deaminases acting on RNA (ADARs): RNA-editing enzymes. Genome Biol. 2004, 5, 209. [CrossRef]

16. George, C.X.; Gan, Z.; Liu, Y.; Samuel, C.E. Adenosine deaminases acting on RNA (ADARs), RNA editing and interferon action. J. Interferon Cytokine Res. 2011, 31, 99-117. [CrossRef] [PubMed]

17. Nishikura, K. Functions and regulation of RNA editing by ADAR deaminases. Annu. Rev. Biochem. 2010, 79, 321-349. [CrossRef] [PubMed]

18. Savva, Y.A.; Rieder, L.E.; Reenan, R.A. The ADAR protein family. Genome Biol. 2012, 13, 252. [CrossRef] [PubMed]

19. Heale, B.S.; Keegan, L.P.; McGurk, L.; Michlewski, G.; Brindle, J.; Stanton, C.M.; Caceres, J.F.; O'connell, M.A. Editing independent effects of ADARs on the miRNA/siRNA pathways. EMBO J. 2009, 28, 3145-3156. [CrossRef]

20. Ota, H.; Sakurai, M.; Gupta, R.; Valente, L.; Wulff, B.E.; Ariyoshi, K.; Iizasa, H.; Davuluri, R.V.; Nishikura, K. ADAR1 forms a complex with Dicer to promote microRNA processing and RNA-induced gene silencing. Cell 2013, 153, 575-589. [CrossRef]

21. Nemlich, Y.; Greenberg, E.; Ortenberg, R.; Besser, M.J.; Barshack, I.; Jacob-Hirsch, J.; Jacoby, E.; Eyal, E.; Rivkin, L.; Prieto, V.G. MicroRNA-mediated loss of ADAR1 in metastatic melanoma promotes tumor growth. J. Clin. Investig. 2013, 123, 2703-2718. [CrossRef] [PubMed]

22. Cho, C.; Myung, S.J.; Chang, S. ADAR1 and MicroRNA; A Hidden Crosstalk in Cancer. Int. J. Mol. Sci. 2017, 18, 799. [CrossRef] [PubMed]

23. Samuel, C.E. Adenosine deaminases acting on RNA (ADARs) are both antiviral and proviral. Virology 2011, 411, 180-193. [CrossRef] [PubMed] 
24. Wang, H.; Wang, G.; Zhang, L.; Zhang, J.; Zhang, J.; Wang, Q.; Billiar, T.R. ADAR1 suppresses the activation of cytosolic RNA-sensing signaling pathways to protect the liver from ischemia/reperfusion injury. Sci. Rep. 2016, 6, 20248. [CrossRef] [PubMed]

25. Ben-Shoshan, S.O.; Kagan, P.; Sultan, M.; Barabash, Z.; Dor, C.; Jacob-Hirsch, J.; Harmelin, A.; Pappo, O.; Marcu-Malina, V.; Ben-Ari, Z.; et al. ADAR1 deletion induces NFkappaB and interferon signaling dependent liver inflammation and fibrosis. RNA Biol. 2017, 14, 587-602. [CrossRef] [PubMed]

26. Ye, X.; Ding, J.; Zhou, X.; Chen, G.; Liu, S.F. Divergent roles of endothelial NF-kappaB in multiple organ injury and bacterial clearance in mouse models of sepsis. J. Exp. Med. 2008, 205, 1303-1315. [CrossRef] [PubMed]

27. Verjans, R.; Peters, T.; Beaumont, F.J.; van Leeuwen, R.; van Herwaarden, T.; Verhesen, W.; Munts, C.; Bijnen, M.; Henkens, M.; Diez, J.; et al. MicroRNA-221/222 family counteracts myocardial fibrosis in pressure overload-induced heart failure. Hypertension 2018, 71, 280-288. [CrossRef]

28. Orecchini, E.; Doria, M.; Michienzi, A.; Giuliani, E.; Vassena, L.; Ciafre, S.A.; Farace, M.G.; Galardi, S. The HIV-1 Tat protein modulates CD4 expression in human T cells through the induction of miR-222. RNA Biol. 2014, 11, 334-338. [CrossRef]

29. Yang, X.; Haurigot, V.; Zhou, S.; Luo, G.; Couto, L.B. Inhibition of hepatitis C virus replication using adeno-associated virus vector delivery of an exogenous anti-hepatitis $C$ virus microRNA cluster. Hepatology 2010, 52, 1877-1887. [CrossRef]

30. Zhang, C.Z.; Han, L.; Zhang, A.L.; Fu, Y.C.; Yue, X.A.; Wang, G.X.; Jia, Z.F.; Pu, P.Y.; Zhang, Q.Y.; Kang, C.S. MicroRNA-221 and microRNA-222 regulate gastric carcinoma cell proliferation and radioresistance by targeting PTEN. BMC Cancer 2010, 10, 367.

31. Garofalo, M.; Di Leva, G.; Romano, G.; Nuovo, G.; Suh, S.S.; Ngankeu, A.; Taccioli, C.; Pichiorri, F.; Alder, H.; Secchiero, P.; et al. miR-221\&222 regulate TRAIL resistance and enhance tumorigenicity through PTEN and TIMP3 downregulation. Cancer Cell 2009, 16, 498-509. [PubMed]

32. Griffiths-Jones, S. The microRNA registry. Nucleic Acids Res. 2004, 32, 109-111. [CrossRef] [PubMed]

33. Zhang, Z.; Li, Y.; Sheng, C.; Yang, C.; Chen, L.; Sun, J. Tanshinone IIA inhibits apoptosis in the myocardium by inducing microRNA-152-3p expression and thereby downregulating PTEN. Am. J. Transl. Res. 2016, 8, 3124-3132. [PubMed]

34. Maisch, B.; Pankuweit, S. Current treatment options in (peri)myocarditis and inflammatory cardiomyopathy. Herz 2012, 37, 644-656. [CrossRef] [PubMed]

35. Hendry, R.G.; Bilawchuk, L.M.; Marchant, D.J. Targeting matrix metalloproteinase activity and expression for the treatment of viral myocarditis. J. Cardiovasc. Transl. Res. 2014, 7, 212-225. [CrossRef]

36. Mody, K.P.; Takayama, H.; Landes, E.; Yuzefpolskaya, M.; Colombo, P.C.; Naka, Y.; Jorde, U.P.; Uriel, N. Acute mechanical circulatory support for fulminant myocarditis complicated by cardiogenic shock. J. Cardiovasc. Transl. Res. 2014, 7, 156-164. [CrossRef] [PubMed]

37. Krol, J.; Loedige, I.; Filipowicz, W. The widespread regulation of microRNA biogenesis, function and decay. Nat. Rev. Genet. 2010, 11, 597-610. [CrossRef] [PubMed]

38. Xu, H.F.; Ding, Y.J.; Zhang, Z.X.; Wang, Z.F.; Luo, C.L.; Li, B.X.; Shen, Y.W.; Tao, L.Y.; Zhao, Z.Q. MicroRNA-21 regulation of the progression of viral myocarditis to dilated cardiomyopathy. Mol. Med. Rep. 2014, 10, 161-168. [CrossRef] [PubMed]

39. Xu, H.F.; Ding, Y.J.; Shen, Y.W.; Xue, A.M.; Xu, H.M.; Luo, C.L.; Li, B.X.; Liu, Y.L.; Zhao, Z.Q. MicroRNA-1 represses Cx43 expression in viral myocarditis. Mol. Cell. Biochem. 2012, 362, 41-48. [CrossRef] [PubMed]

40. Massilamany, C.; Huber, S.A.; Cunningham, M.W.; Reddy, J. Relevance of molecular mimicry in the mediation of infectious myocarditis. J. Cardiovasc. Transl. Res. 2014, 7, 165-171. [CrossRef] [PubMed]

41. Koenig, A.; Sateriale, A.; Budd, R.C.; Huber, S.A.; Buskiewicz, I.A. The role of sex differences in autophagy in the heart during coxsackievirus B3-induced myocarditis. J. Cardiovasc. Transl. Res. 2014, 7, 182-191. [CrossRef] [PubMed]

42. Antoniak, S.; Mackman, N. Coagulation, protease-activated receptors, and viral myocarditis. J. Cardiovasc. Transl. Res. 2014, 7, 203-211. [CrossRef]

43. Rabinovici, R.; Kabir, K.; Chen, M.H.; Su, Y.J.; Zhang, D.X.; Luo, X.X.; Yang, J.H. ADAR1 is involved in the development of microvascular lung injury. Circ. Res. 2001, 88, 1066-1071. [CrossRef] 
44. Yang, J.H.; Luo, X.X.; Nie, Y.Z.; Su, Y.J.; Zhao, Q.C.; Kabir, K.; Zhang, D.X.; Rabinovici, R. Widespread inosine-containing mRNA in lymphocytes regulated by ADAR1 in response to inflammation. Immunology 2003, 109, 15-23. [CrossRef]

45. Gandy, S.Z.; Linnstaedt, S.D.; Muralidhar, S.; Cashman, K.A.; Rosenthal, L.J.; Casey, J.L. RNA editing of the human herpesvirus 8 kaposin transcript eliminates its transforming activity and is induced during lytic replication. J. Virol. 2007, 81, 13544-13551. [CrossRef] [PubMed]

46. Jiang, Q.F.; Crews, L.A.; Barrett, C.L.; Chun, H.J.; Court, A.C.; Isquith, J.M.; Zipeto, M.A.; Goff, D.J.; Minden, M.; Sadarangani, A.; et al. ADAR1 promotes malignant progenitor reprogramming in chronic myeloid leukemia. Proc. Natl. Acad. Sci. USA 2013, 110, 1041-1046. [CrossRef] [PubMed]

47. Chen, L.L.; Li, Y.; Lin, C.H.; Chan, T.H.M.; Chow, R.K.K.; Song, Y.Y.; Liu, M.; Yuan, Y.F.; Fu, L.; Kong, K.L.; et al. Recoding RNA editing of AZIN1 predisposes to hepatocellular carcinoma. Nat. Med. 2013, 19, $209-216$. [CrossRef] [PubMed]

48. Hoopengardner, B.; Bhalla, T.; Staber, C.; Reenan, R. Nervous system targets of RNA editing identified by comparative genomics. Science 2003, 301, 832-836. [CrossRef] [PubMed]

49. Rueter, S.M.; Dawson, T.R.; Emeson, R.B. Regulation of alternative splicing by RNA editing. Nature 1999, 399, 75-80. [CrossRef]

50. Chunzi, S.; Masayuki, S.; Yusuke, S.; Kazuko, N. Functions of the RNA editing ADAR1 and their relevance to human diseases. Genes 2016, 7, 129.

51. Kawahara, Y.; Zinshteyn, B.; Sethupathy, P.; Iizasa, H.; Hatzigeorgiou, A.G.; Nishikura, K. Redirection of silencing targets by adenosine-to-inosine editing of miRNAs. Science 2007, 315, 1137-1140. [CrossRef]

52. Hartner, J.C.; Walkley, C.R.; Lu, J.; Orkin, S.H. ADAR1 is essential for the maintenance of hematopoiesis and suppression of interferon signaling. Nat. Immunol. 2009, 10, 109-115. [CrossRef] [PubMed]

53. Liu, X.; Cheng, Y.; Zhang, S.; Lin, Y.; Yang, J.; Zhang, C. A necessary role of miR-221 and miR-222 in vascular smooth muscle cell proliferation and neointimal hyperplasia. Circ. Res. 2009, 104, 476-487. [CrossRef] [PubMed]

54. Huang, J.; Kontos, C.D. Inhibition of vascular smooth muscle cell proliferation, migration, and survival by the tumor suppressor protein PTEN. Arterioscler. Thromb. Vasc. Biol. 2002, 22, 745-751. [CrossRef] [PubMed]

55. Nisbet, R.E.; Bland, J.M.; Kleinhenz, D.J.; Mitchell, P.O.; Walp, E.R.; Sutliff, R.L.; Hart, C.M. Rosiglitazone attenuates chronic hypoxia-induced pulmonary hypertension in a mouse model. Am. J. Respir. Cell Mol. Biol. 2010, 42, 482-490. [CrossRef] [PubMed]

56. Gu, J.; Tamura, M.; Yamada, K.M. Tumor suppressor PTEN inhibits integrin- and growth factor-mediated mitogen-activated protein (MAP) kinase signaling pathways. J. Cell Biol. 1998, 143, 1375-1383. [CrossRef]

57. Moon, S.K.; Kim, H.M.; Kim, C.H. PTEN induces G1 cell cycle arrest and inhibits MMP-9 expression via the regulation of NF-kappaB and AP-1 in vascular smooth muscle cells. Arch. Biochem. Biophys. 2004, 421, 267-276. [CrossRef]

58. Tamguney, T.; Stokoe, D. New insights into PTEN. J. Cell Sci. 2007, 120, 4071-4079. [CrossRef]

59. Van de Sande, T.; De Schrijver, E.; Heyns, W.; Verhoeven, G.; Swinnen, J.V. Role of the phosphatidylinositol $3^{\prime}$-kinase/PTEN/Akt kinase pathway in the overexpression of fatty acid synthase in LNCaP prostate cancer cells. Cancer Res. 2002, 62, 642-646.

60. Oudit, G.Y.; Penninger, J.M. Cardiac regulation by phosphoinositide 3-kinases and PTEN. Cardiovasc. Res. 2009, 82, 250-260. [CrossRef]

61. Oudit, G.Y.; Sun, H.; Kerfant, B.G.; Crackower, M.A.; Penninger, J.M.; Backx, P.H. The role of phosphoinositide-3 kinase and PTEN in cardiovascular physiology and disease. J. Mol. Cell. Cardiol. 2004, 37, 449-471. [CrossRef] [PubMed]

62. Gong, L.; Zhang, W.; Yuan, Y.; Xing, X.; Li, H.; Zhao, G. miR-222 promotes invasion and migration of ovarian carcinoma by targeting PTEN. Oncol. Lett. 2018, 16, 984-990. [CrossRef] [PubMed]

63. Glass, C.; Singla, D.K. MicroRNA-1 transfected embryonic stem cells enhance cardiac myocyte differentiation and inhibit apoptosis by modulating the PTEN/Akt pathway in the infarcted heart. Am. J. Physiol. Heart Circ. Physiol. 2011, 301, 2038-2049. [CrossRef] [PubMed]

64. Klingel, K.; Hohenadl, C.; Canu, A.; Albrecht, M.; Seemann, M.; Mall, G.; Kandolf, R. Ongoing enterovirus-induced myocarditis is associated with persistent heart muscle infection: Quantitative analysis of virus replication, tissue damage, and inflammation. Proc. Natl. Acad. Sci. USA 1992, 89, 314-318. [CrossRef] [PubMed] 
65. Kandolf, R.; Selinka, H.; Klingel, K. Pathogenesis of Coxsackievirus B infections. Mol. Biol. Picornaviruses 2002, 67, 405-413.

66. Rahnefeld, A.; Klingel, K.; Schuermann, A.; Diny, N.L.; Althof, N.; Lindner, A.; Bleienheuft, P.; Savvatis, K.; Respondek, D.; Opitz, E.; et al. Ubiquitin-Like Protein ISG15 (Interferon-Stimulated Gene of 15 kDa) in host defense against heart failure in a mouse model of virus-induced cardiomyopathy. Circulation 2014, 130, 1589-1600. [CrossRef] [PubMed]

67. Gui, J.; Yue, Y.; Chen, R.; Xu, W.; Xiong, S. A20 (TNFAIP3) alleviates CVB3-induced myocarditis via inhibiting NF-kappaB signaling. PLoS ONE 2012, 7, e46515. [CrossRef] [PubMed]

(C) 2019 by the authors. Licensee MDPI, Basel, Switzerland. This article is an open access article distributed under the terms and conditions of the Creative Commons Attribution (CC BY) license (http:// creativecommons.org/licenses/by/4.0/). 